Exp. Anim. 68(2), 147-158, 2019

\title{
-Original-
}

\section{AlM-deficient mouse fed a high-trans fat, high-cholesterol diet: a new animal model for nonalcoholic fatty liver disease}

\author{
Ginga KOMATSU'), Toru NONOMURA ${ }^{2)}$, Mai SASAKI'), Yuki ISHIDA2), \\ Satoko ARAI ${ }^{1)}$ and Toru MIYAZAKI ${ }^{1,4,5)}$ \\ 1) Laboratory of Molecular Biomedicine for Pathogenesis, Center for Disease Biology and Integrative Medicine, \\ Faculty of Medicine, The University of Tokyo, 7-3-1 Hongo, Bunkyo-ku, Tokyo 113-0033, Japan \\ 2) Research Division Pharmacology Group, New Drug Research Center Inc., 452-1 Toiso, Eniwa-shi, Hokkaido \\ 061-1405, Japan \\ 3) Research Division Pathology Group, New Drug Research Center Inc., 452-1 Toiso, Eniwa-shi, Hokkaido 061-1405, \\ Japan \\ 4) AMED-CREST, Japan Agency for Medical Research and Development, 7-3-1 Hongo, Bunkyo-ku, Tokyo 113-0033, \\ Japan \\ ${ }^{5)}$ Max Planck-The University of Tokyo Center for Integrative Inflammology, 7-3-1 Hongo, Bunkyo-ku, Tokyo 113- \\ 0033, Japan
}

\begin{abstract}
Owing to changes in lifestyle, nonalcoholic fatty liver disease (NAFLD) is becoming a common form of chronic liver injury. NAFLD comprises a wide variety of disease stages, from simple steatosis to nonalcoholic steatohepatitis, which is a risk factor for the development of hepatocellular carcinoma (HCC). Because animal models for NAFLD are needed to investigate the precise pathogenesis, we aimed to establish a new mouse model employing mice deficient for apoptosis inhibitor of macrophage $\left(A I M^{--}\right)$, which exhibit accelerated lipid storage in the liver and high susceptibility to developing HCC in response to a high-fat diet (HFD). $A I M^{-/-}$mice were fed the D09100301 diet, which contains $40 \mathrm{kcal} \%$ fat (trans fat $30 \mathrm{kcal} \%$ ), high cholesterol (2\%), and 40 $\mathrm{kcal} \%$ carbohydrates ( $20 \mathrm{kcal} \%$ fructose), and then features of obesity and NAFLD including steatosis, inflammation, fibrosis, and HCC development were analyzed. Although a comparable grade of liver steatosis was promoted in $A / M^{-/-}$mice by the D09100301 diet and the standard HFD (60 kcal\% largely lard fat), significantly less lipid storage in visceral fat was observed when the mice were fed the D09100301 diet. Accelerated liver inflammation was promoted by the D09100301 diet compared with the HFD, but interestingly, HCC development was decreased in mice fed the D09100301 diet. Our findings suggest that $A I M^{-/-}$mice fed the D09100301 diet exhibited a phenotype that resembled nonobese NAFLD patients and thus could be an appropriate tool to study the pathophysiology by which obesity increases the risk of HCC.

Key words: apoptosis inhibitor of macrophage (AIM), D09100301 high-trans fat high-cholesterol diet, hepatocellular carcinoma (HCC), nonalcoholic fatty liver disease (NAFLD), obesity
\end{abstract}




\section{Introduction}

Chronic liver injury has high mortality, and its most common cause has been hepatitis virus $\mathrm{C}$ infection, which leads to low-grade, chronic liver inflammation, followed by liver fibrosis progressing to cirrhosis. Alcohol, toxins, autoimmunity, and genetic disorders such as hemochromatosis also, but not frequently, contribute to the initiation of chronic liver injury $[8,15,19]$. In recent decades, obesity-associated nonalcoholic fatty liver disease (NAFLD), which comprises a wide spectrum ranging from "benign" simple steatosis to progressive inflammation and fibrosis called nonalcoholic steatohepatitis (NASH), has been observed as a state of chronic liver injury in a rapidly growing number of patients due to rapid and drastic changes in lifestyle and eating habits in modern society $[1,36,40]$. Indeed, NAFLD currently affects more than $25 \%$ of the general population in many countries $[4,24,45]$. Of these, up to $15-20 \%$ of NASH patients progress to cirrhosis over 10 to 20 years $[6,27,39]$. In patients with either hepatitis virus infection or NASH, liver cirrhosis is a prominent risk factor for the development of hepatocellular carcinoma (HCC) $[5,7,16,33]$. Intriguingly, however, it has recently become apparent that $\mathrm{HCC}$ also often occurs without severe fibrosis/cirrhosis in NASH patients, which is one of the unique and complicated pathologic characteristics of NAFLD [14, 20, 41, 42]. Excellent animal models for NAFLD are certainly desired to determine the precise pathogenic mechanisms by which steatosis progresses to NASH and HCC and to establish efficient therapies for this chronic liver disease. So far, several useful models for NAFLD, either diet-induced or generated by genetic modifications, have been reported [17, 43, 44]. Of these, we previously showed that mice deficient in apoptosis inhibitor of macrophage (AIM, encoded by the $C d 5 l$ gene) $\left(A I M^{-/-}\right.$mice) exhibit many characteristics of NAFLD when fed a high-fat $\operatorname{diet}(\mathrm{HFD})$ [26].

AIM is a circulating protein initially identified as a supporter of macrophage survival [29]. Interestingly, AIM is associated with the IgM pentamer in blood, which protects AIM from renal excretion and thus maintains circulating AIM at a relatively high concentration (approximately $5 \mu \mathrm{g} / \mathrm{ml}$ in mice and humans) [3, 22, 30, 47]. An interesting molecular characteristic of AIM is that in the obese state, AIM is incorporated via CD36mediated endocytosis into adipocytes and hepatocytes where it inactivates cytoplasmic fatty acid synthase (FASN) through direct binding [23, 26]. This response reduces the production of lipid-droplet-coating proteins such as fat-specific protein 27 and perilipin, thereby decreasing triacylglycerol (TG) deposition within adipocytes or hepatocytes $[18,23]$. Accordingly, in $A_{I M}^{-/-}$ mice fed a standard HFD (HFD32; fat $60 \mathrm{kcal} \%$, most of which is from lard), adipocyte hypertrophy is more advanced, and the volume of visceral adipose tissue is greater than in wild-type mice fed HFD32. Parallel results are observed in the liver, where the state of HFD32induced liver steatosis is markedly accelerated in $\mathrm{AIM}^{-/-}$ mice compared with wild-type mice [26].

An additional important AIM function highlighted in the liver is induction of $\mathrm{HCC}$ cell elimination via complement activation $[26,28]$. Once hepatocytes have undergone malignant transformation to HCC cells, AIM no longer undergoes endocytosis. This phenotypic change of AIM is possibly due to defective endocytosis, which is a common feature of many different types of cancer cells. As a result, AIM accumulates on the surface of HCC cells after AIM-CD36 binding, with insufficient cellular incorporation of AIM. Interestingly, cell surface AIM interacts with various regulators of complement activation and suppresses their function, resulting in specific activation of a complement cascade against the cancer cells. This leads to necrosis of AIM-associated HCC cells, thereby preventing overall liver tumor development $[26,28]$. Indeed, most $A I M^{-/-}$mice bear multiple HCC tumors when fed HFD32 for a year; in contrast, wild-type mice do not develop HCC tumors. Such HCC tumor susceptibility was also observed in $A I M^{-/-}$mice fed a high-fructose diet [38].

In view of these findings showing that the $\mathrm{AIM}^{-/-}$ mouse is a useful tool to easily obtain a diet-induced NAFLD state with HCC, in this study, we fed $\mathrm{AIM}^{-/-}$ mice with a specific HFD (D09100301) in which the greatest source of fat is trans fat. This diet contains 40 $\mathrm{kcal} \%$ fat (trans fat $30 \mathrm{kcal} \%)$, high cholesterol (2\%), and $40 \mathrm{kcal} \%$ carbohydrates ( $20 \mathrm{kcal} \%$ fructose). Here, we investigated whether $A I M^{--}$mice exhibited different stages of NAFLD in response to the unique D09100301 diet.

\section{Materials and Methods}

Mice

$A I M^{-/-}$mice [29] that had been backcrossed to 
Table 1. Composition of the HFD32 and D09100301 diets

\begin{tabular}{lccllc}
\hline \multicolumn{1}{c}{$\begin{array}{c}\text { High-fat diet } \\
\text { (HFD32) }\end{array}$} & & & \multicolumn{2}{c}{$\begin{array}{c}\text { High-trans-fat/cholesterol diet } \\
\text { (D09100301) }\end{array}$} \\
\cline { 1 - 2 } \cline { 5 - 6 } Ingredient & $\mathrm{g} / 100 \mathrm{~g}$ & & \multicolumn{2}{c}{ Ingredient } & $\mathrm{g} / 100 \mathrm{~g}$ \\
\hline Casein & 24.5 & & Casein & 22.12 \\
L-cystine & 0.43 & & & L-cystine & 0.33 \\
\hline Maltodextrin & 8.25 & & Maltodextrin & 11.06 \\
Sucrose & 6.75 & & Sucrose & 10.62 \\
Lactose & 6.928 & & Fructose & 22.12 \\
\hline Cellulose & 5.5 & & Cellulose & 5.53 \\
\hline Safflower oil (high oleic acid) & 20 & & Soybean oil & 2.77 \\
Lard & 15.88 & & Lard & 2.21 \\
& & & Shortening (Primex) & 14.93 \\
& & & Cholesterol & 1.99 \\
\hline Vitamin mix & 1.4 & & Vitamin mix & 1.11 \\
Mineral mix & 5 & & Mineral mix & 1.11 \\
Choline bitartrate & 0.36 & & Choline bitartrate & 0.22 \\
Tertiary butylhydroquinone & 0.002 & & Calcium carbonate & 0.61 \\
Egg white & 5 & & Potassium citrate & 1.83 \\
& & & Dicalcium phosphate & 1.44 \\
& & & FD\&C Yellow Dye \#5 & 0.01 \\
\hline
\end{tabular}

Table 2. Real-time PCR primer sequences

\begin{tabular}{lll}
\hline \multicolumn{1}{c}{ Gene name } & \multicolumn{1}{c}{ Forward (5' to 3') } & \multicolumn{1}{c}{ Reverse (5' to 3') } \\
\hline Tumor necrosis factor $(\mathrm{Tnf})$ & ACAGAAAGCATGATCCGCG & GCCCCCCATCTTTTGGG \\
Interleukin 1 beta $(\mathrm{Ill} / \mathrm{b})$ & CTGGTGTGTGACGTTCCCATTA & CCGACAGCACGAGGCTTT \\
Chemokine (C-C motif) ligand 2 $(\mathrm{Ccl})$ & CATCCACGTGTTGGCTCA & GATCATCTTGCTGGTGAATGAGT \\
Adhesion G protein-coupled receptor E1 $(\mathrm{Adgrel})$ & CCTGGACGAATCCTGTGAAG & GGTGGGACCACAGAGAGTTG \\
Glyceraldehyde-3-phosphate dehydrogenase $(\mathrm{Gapdh})$ & AACTTTGGCATTGTGGAAGG & GGATGCAGGGATGATGTTCT \\
\hline
\end{tabular}

C57BL/6J (B6) for 13 generations were used for the experiments. HFD32 was purchased from CLEA (Japan). D09100301 was purchased from Research Diets (New Brunswick, NJ, USA). The compositions of the diets are described in Table 1. All mice were maintained under specific-pathogen-free conditions.

\section{Quantitative real-time reverse transcriptase PCR}

The total RNA was isolated using TRIzol reagent (Thermo Fisher Scientific). cDNA was synthesized with SuperScript 3 Reverse Transcriptase (Thermo). Quantitative real-time PCR analysis was performed using PowerUp SYBR Green Master Mix (Thermo) on a QuantStudio 3 Real-time PCR system (Applied Biosystems). The level of Gapdh expression was used to normalize the data. The primer sequences used are presented in Table 2.

\section{Histological analyses}

Liver samples were fixed in 10\% Formaldehyde Neu- tral Buffer Solution for $24 \mathrm{~h}$ and embedded in paraffin. Hematoxylin and eosin (H\&E) staining and Sirius Red staining were performed using $3 \mu \mathrm{m}$ sections of paraffinembedded liver blocks. NAFLD Activity Score (NAS) was determined on H\&E-stained sections as previously described [21]. For Sirius Red staining, liver sections were incubated with $0.1 \%$ direct red in saturated picric acid for $1 \mathrm{~h}$ at room temperature with protection from exposure to light.

\section{Biochemical analysis}

Serum biochemical variables (aspartate aminotransferase, AST; alanine aminotransferase, ALT; alkaline phosphatase, ALP; total bilirubin, T-Bil; triglyceride, TG; total cholesterol, T-Chol; low-density lipoprotein, LDL; high-density lipoprotein, HDL; nonesterified fatty acid, NEFA) were measured with a 7070 biochemical automatic analyzer (Hitachi High-Technologies Corporation, Tokyo, Japan). 

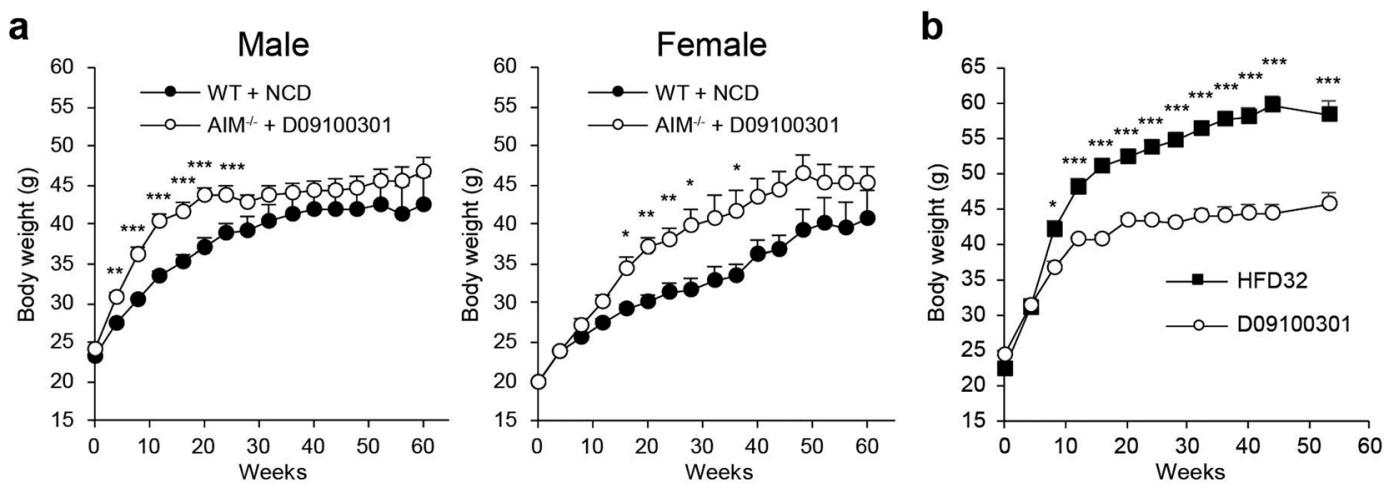

Fig. 1. Gain of body weight: (a, b) Body weight of wild-type mice fed the NCD and $A I M^{-1-}$ mice fed the D09100301 diet (males, $n=5-7$ in each group; females, $n=5$ in each group).

\section{Liver TG and cholesterol content}

Liver tissues were homogenized in chloroform/methanol $(2: 1, \mathrm{v} / \mathrm{v})$, and lipid extracts were prepared by the Folch method. Hepatic TG and cholesterol levels were measured using commercial kits (Wako, Japan) according to the manufacturer's instructions.

\section{Statistical analysis}

All results are presented as the mean \pm SEM. Statistically significant differences between mean values were determined using a two-tailed Mann-Whitney test $(* * * P<0.005, * * P<0.01, * P<0.05)$.

\section{Results}

\section{Obesity in AIM ${ }^{-1-}$ mice fed the D09100301 diet}

$A I M^{-/-}$mice were challenged with the D09100301 diet for 60 weeks, and body weight was recorded every week. As shown in Fig. 1a, in male $A I M^{-/-}$mice, the increase in body weight was prominent during the first 20 weeks and nearly plateaued thereafter. In contrast, the gain in body weight was milder in female mice than in male mice but continued consistently until 50 weeks. After 60 weeks on this diet, both males and females exhibited a body weight that was largely comparable to that of wild-type mice of the same age fed a normal chow $\operatorname{diet}(\mathrm{NCD})$ (Fig. 1a). In a different set of experiments, male $A I M^{-/-}$mice were also fed with the HFD32 diet (60 kcal\% mostly lard fat), and the gain in body weight was compared with the data in Fig. 1a. As demonstrated in Fig. 1b, from an early time point (10 weeks), the gain in body weight was significantly greater in mice fed the HFD32 diet than those fed the D09100301 diet. The compositions of both diets are presented comparatively in Table 1.

The weights of different organs were also assessed after mice were fed the diets for 12, 24, and 60 weeks. Interestingly, although visceral fat weight increased after 12 weeks of the D09100301 diet and was significantly larger than that in wild-type mice fed the NCD, it no longer increased significantly thereafter (Fig. 2a). In female $A I M^{-1-}$ mice, visceral fat weight was comparable to that in wild-type mice fed the NCD throughout the period (Fig. 2a). Visceral fat was significantly smaller in male $A I M^{-/-}$mice fed the D09100301 diet compared with those fed the HFD32 diet after 12 weeks (Fig. 2b). In contrast, liver weight was remarkably increased in both male and female $A I M^{-/-}$mice fed the D09100301 diet (Fig. 2a) and was similar in male $A I M^{-/-}$mice fed either the D09100301 diet or HFD32 diet (Fig. 2b). Thus, it is likely that the D09100301 diet promoted lipid storage specifically in the liver rather than in visceral fat. In other organs, such as the kidney, heart, and lung, the weight gain induced by the D09100301 diet was not significant and was nearly comparable with that in wildtype mice fed the NCD (Fig. 2c). However, splenic weight gain was more accelerated in $A I M^{-/-}$mice fed the D09100301 diet than in wild-type mice fed the NCD (Fig. 2c). This might reflect the chronic inflammatory state induced by obesity and/or liver steatosis in mice fed the D09100301 diet [2, 32]. Serum cholesterol levels (both low-density lipoprotein and high-density lipoprotein levels) and nonesterified fatty acid levels were significantly increased in both male and female $\mathrm{AIM}^{-/-}$mice fed the D09100301 diet, whereas serum TG levels were even lower in IIM $^{-/-}$mice fed the D09100301 diet than in wild-type mice fed the NCD (Fig. 2d). 
a

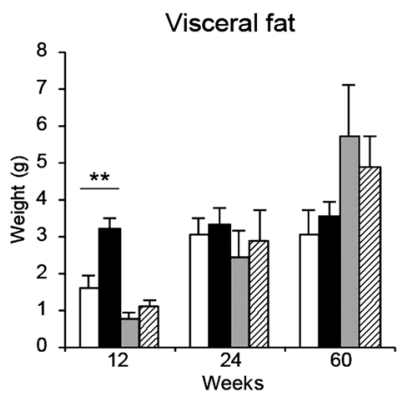

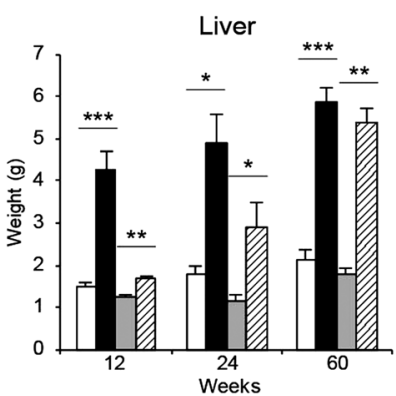

$\square W T(M)+N C D$

- $\mathrm{AIM}^{-1}(\mathrm{M})$

+ D09100301

$\square W T(F)+N C D$

因 AIM $^{-1}(\mathrm{~F})$

+ D09100301 b

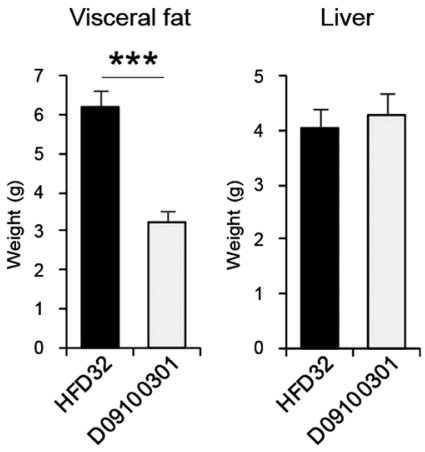

C

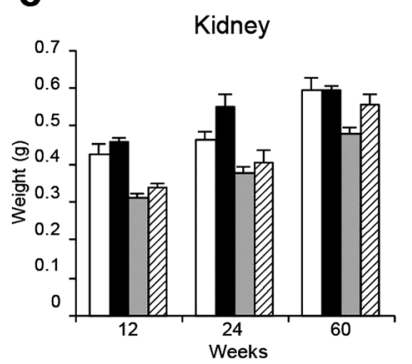

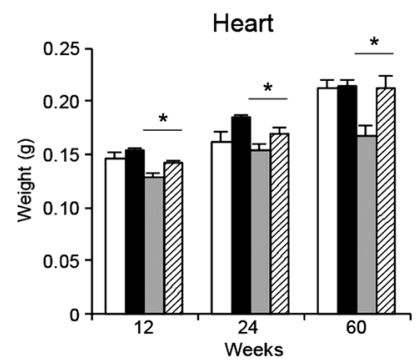
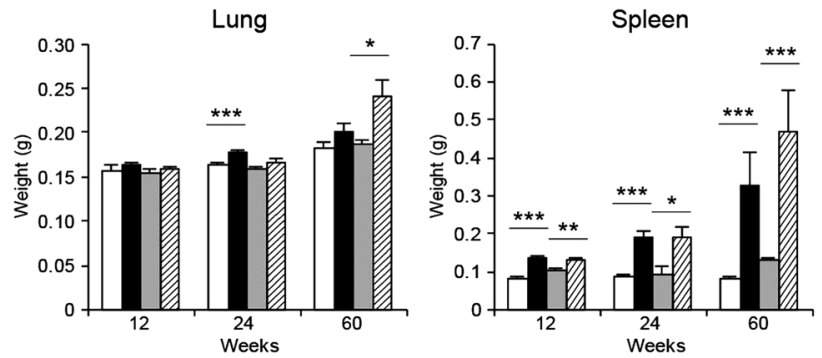

d
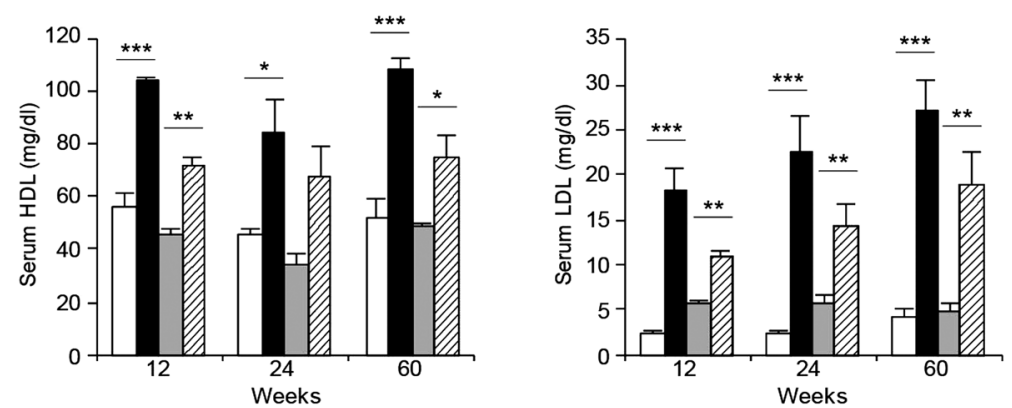

$\square \mathrm{WT}(\mathrm{M})+\mathrm{NCD}$

AIM ${ }^{-1}(\mathrm{M})$

+ D09100301
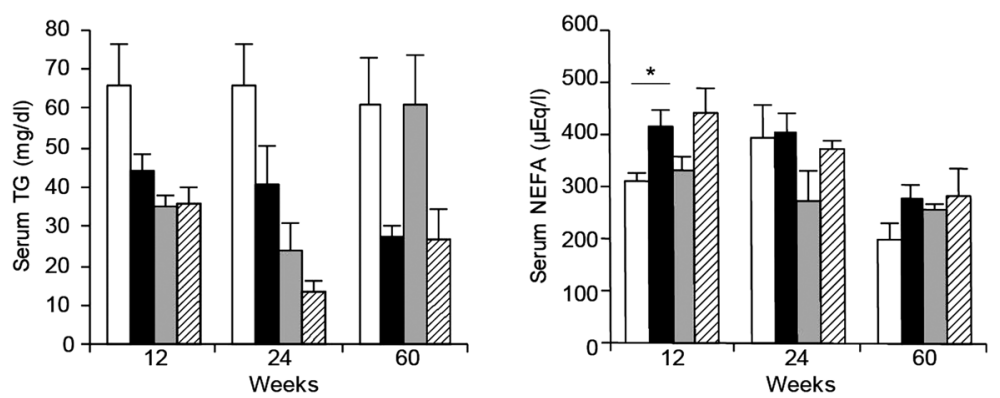

$\square \mathrm{WT}(\mathrm{F})+\mathrm{NCD}$

目 AIM $^{-1}(\mathrm{~F})$

+ D09100301

Fig. 2. Obese state in $A I M^{-1-}$ mice fed the D09100301 diet: (a, b) Weights of visceral fat and the liver in mice fed the NCD (wild-type), D09100301 diet or HFD32 diet $\left(A I M^{-/-}\right)$for the indicated period. (c) Weights of various organs. (d) Serum HDL, LDL, TG, and NEFA levels (males, $\mathrm{n}=5-7$ in each group; females, $\mathrm{n}=5$ in each group).

Liver steatosis promoted by the D09100301 diet in AIM $^{-1-}$ mice

Having observed that the D09100301 diet affected the liver condition specifically, we then assessed the state of liver steatosis in $A I M^{-/-}$mice fed the D09100301 diet. Histologic analysis revealed marked liver steatosis after a 12-week diet in both male and female $A I M^{-1-}$ mice (Fig. 3a). The steatosis score was $3.06(>66 \%$ area) in 
a

Male
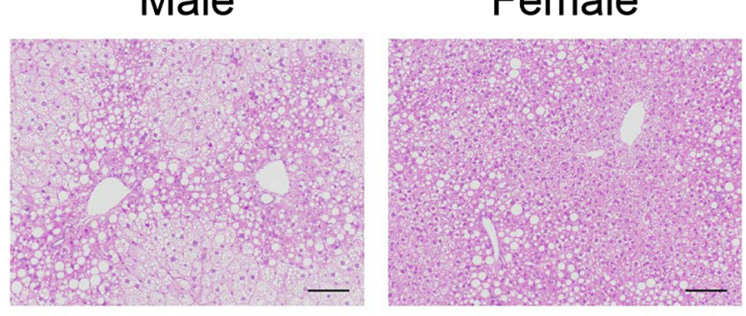

b

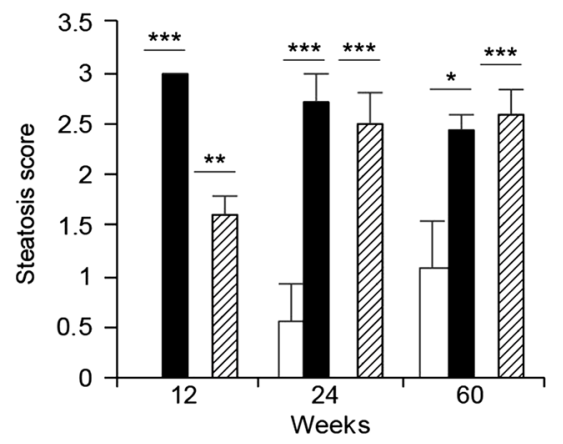

C

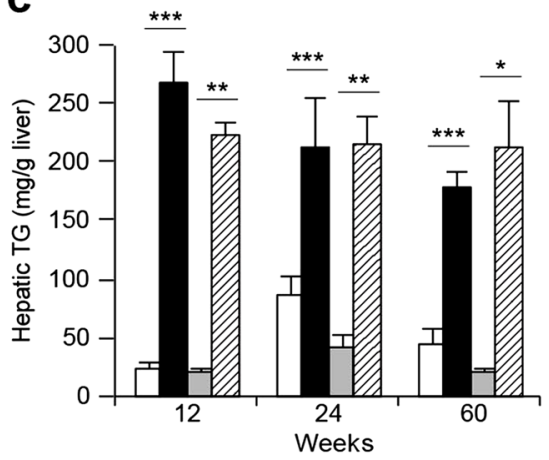

e
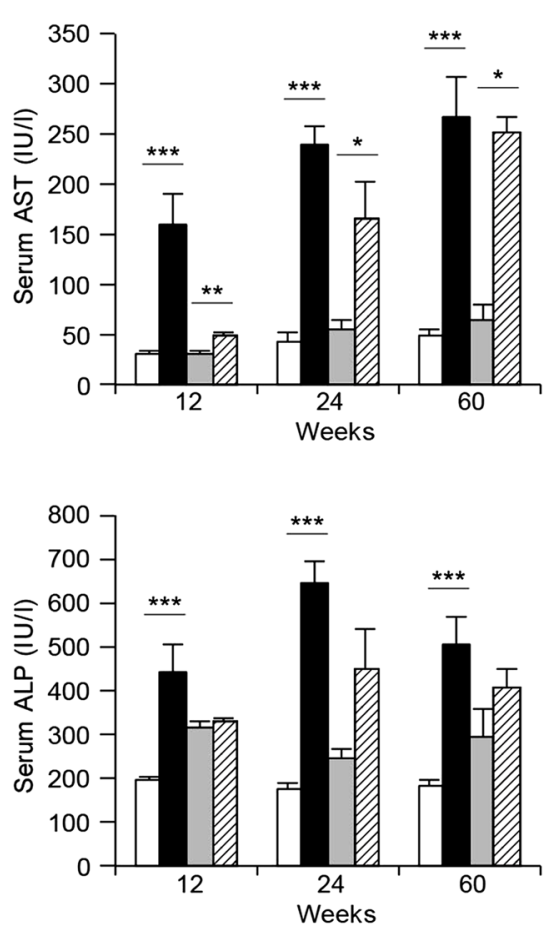

d

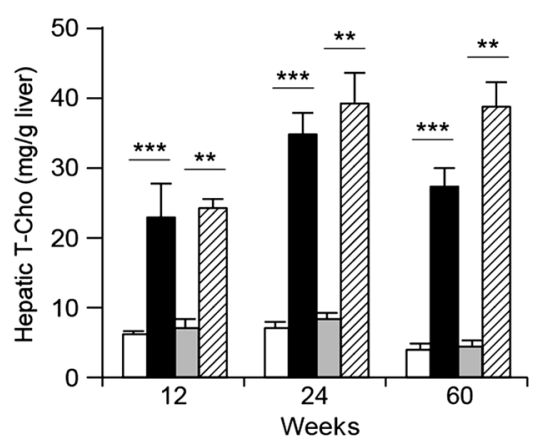

$\square W T(M)+N C D$

- $\mathrm{AIM}^{-1-}(\mathrm{M})$

+ D09100301

$\square W T(F)+N C D$

目 $\mathrm{AIM}^{-1}(\mathrm{~F})$

+ D09100301

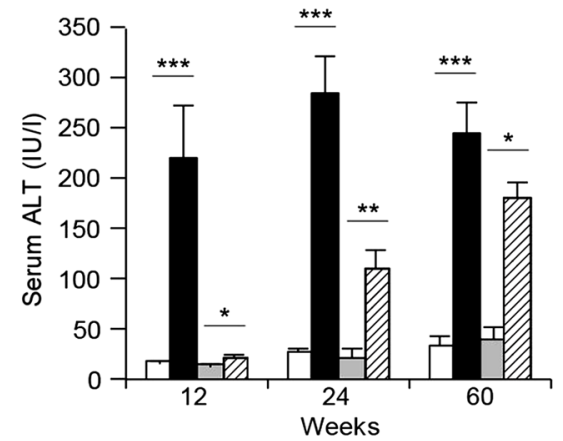

$\square W T(M)+N C D$

- $\mathrm{AIM}^{-1-(\mathrm{M})}$

+ D09100301

$\square \mathrm{WT}(\mathrm{F})+\mathrm{NCD}$

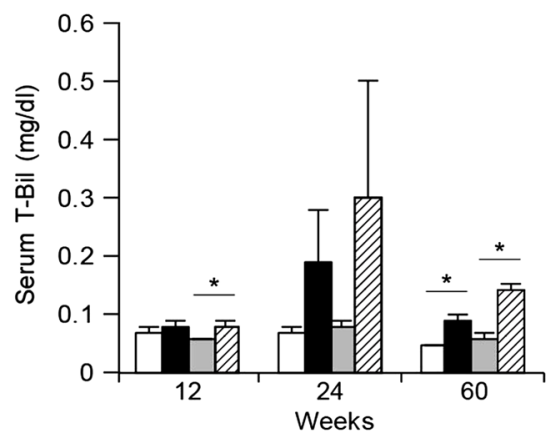

目 $\mathrm{AIM}^{-1-}(\mathrm{F})$

$+\mathrm{D} 09100301$

Fig. 3. Liver steatosis promoted by the D09100301 diet in $A I M^{-/-}$mice: (a) Representative photomicrographs of the liver (hematoxylin-eosin staining) in $A I M^{-/-}$mice (male and female) fed the D09100301 diet for 12 weeks. Scale bars, $100 \mu \mathrm{m}$. (b) Steatosis score in mice fed the NCD (wild-type) or D09100301 diet $\left(A I M^{-/-}\right)$for the indicated period. (c, d) Intrahepatic TG and cholesterol levels in mice. (e) Serum AST, ALT, ALP, and T-Bil levels in mice (male, $\mathrm{n}=7$ in each group; female, $\mathrm{n}=5$ in each group). 
a

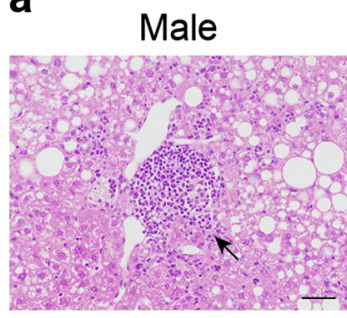

Female

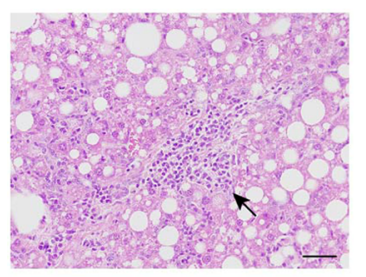

b

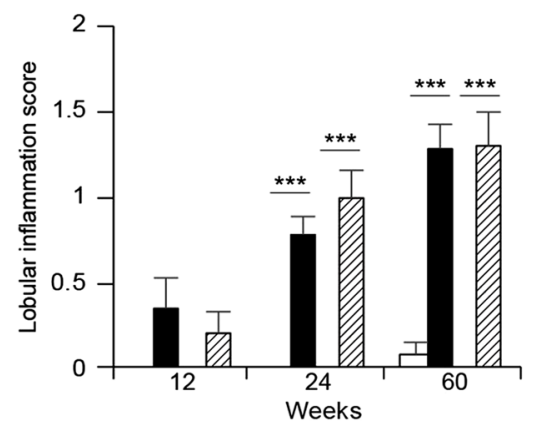

C

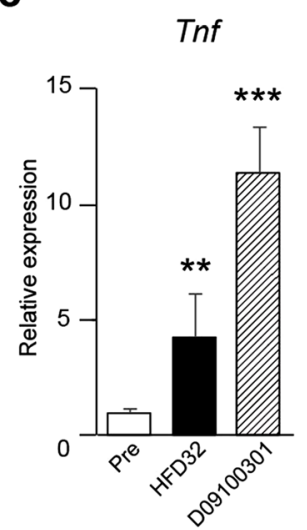

e

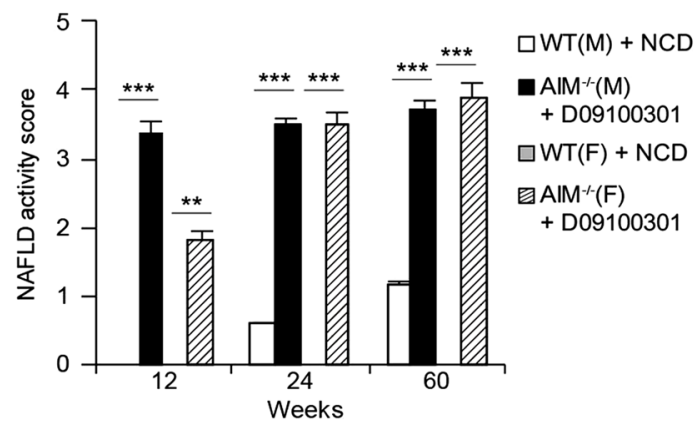

d

Adgre1 (F4/80)
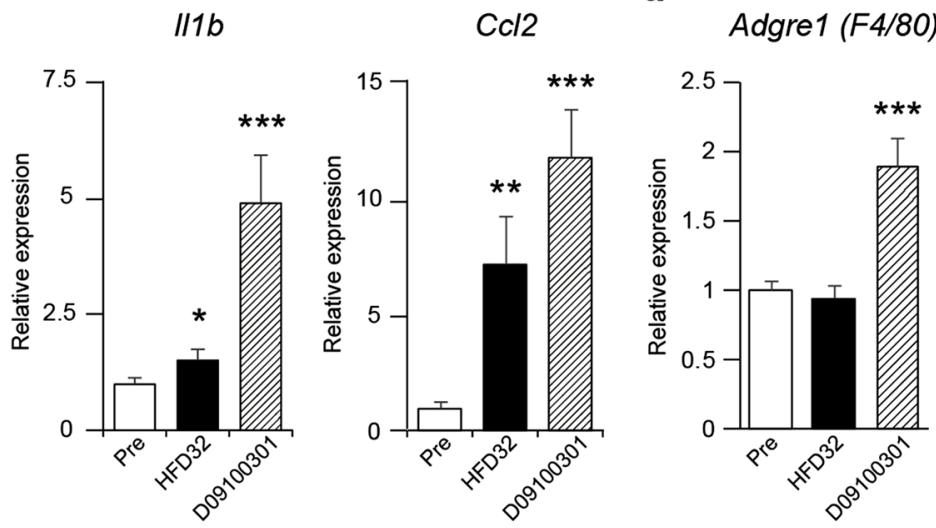

Fig. 4. Inflammatory states in the liver in $A I M^{-1-}$ mice fed the D09100301 diet: (a) Representative photomicrographs of the liver (hematoxylin-eosin staining) in $A I M^{-/-}$mice (male and female) fed the D09100301 diet for 12 weeks. Scale bars, $50 \mu \mathrm{m}$. (b) Lobular inflammation score (males, $\mathrm{n}=7$ in each group; females, $\mathrm{n}=5$ in each group). (c, d) QPCR analysis of mRNA expression of various inflammatory genes (c) and the pan-macrophage marker Adgrel (d) in $A^{\prime} M^{-1}$ mice fed the D09100301 diet for 12 weeks (pre [before the diet], $n=5$; HFD32, $n=5$; D09100301, n=7). (e) NAFLD activity score (male, $n=7$ in each group; female, $\mathrm{n}=5$ in each group).

males and $1.5 \pm 0.2$ in females at 12 weeks, which was largely equivalent to the scores at 24 and 60 weeks in males, and the score increased until 60 weeks, reaching $2.4 \pm 0.2$ in males (Fig. 3b). Accordingly, intrahepatic TG levels were remarkably high $(180-270 \mathrm{mg} / \mathrm{g}$ liver tissue) at all analyzed time points (12, 24, and 60 weeks) (Fig. 3c). Intrahepatic cholesterol levels were also increased up to $23-40 \mathrm{mg} / \mathrm{g}$ liver tissue in both male and female mice (Fig. 3d). Consistent with the prominent steatosis, serum levels of various biomarkers for liver injury increased significantly. As shown in Fig. 3e, the levels of aspartate aminotransferase, alanine aminotransferase, and alkaline phosphatase (ALP) were high starting at 12 weeks, particularly in male mice. The increase in total bilirubin levels was not as robust but was significant in both male and female mice after 60 weeks of the diet (Fig. 3e).
Inflammatory and fibrotic states in the AIM-/- liver

Next, we analyzed the inflammatory state in the liver in $A I M^{-/-}$mice fed the D09100301 diet. Liver histology showed inflammatory foci in male and female mice (Fig. $4 \mathrm{a})$, and their number increased along with the diet period as represented by the lobular inflammation score (Fig. 4b). mRNA levels of inflammatory cytokines such as Tnfa, $I l l b$, and $C c l 2$ increased significantly in the liver after being fed the D09100301 diet for 12 weeks (Fig. 4c). Importantly, the levels were markedly higher in $A I M^{-/-}$mice fed the D09100301 diet than in those fed the HFD32 diet (Fig. 4c). In addition, the mRNA level of Adgre 1, encoding the pan-macrophage marker F4/80, also increased significantly in $A I M^{-/-}$mice fed the D09100301 diet but did not increase significantly in those fed the HFD32 diet, suggesting that the D09100301 diet might recruit inflammatory macrophages into the liver to a greater degree than the HFD32 diet (Fig. 4d). Thus, it appears that liver inflammation followed by 


\section{D09100301}

12 weeks

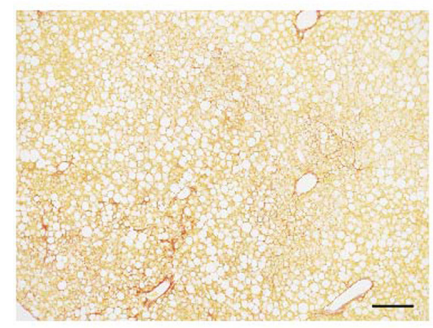

24 weeks

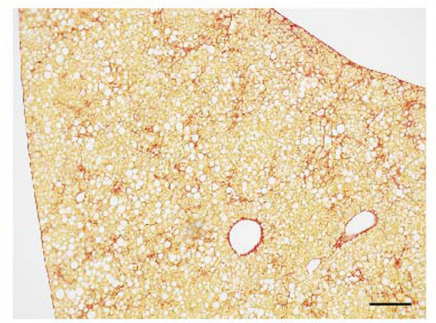

60 weeks

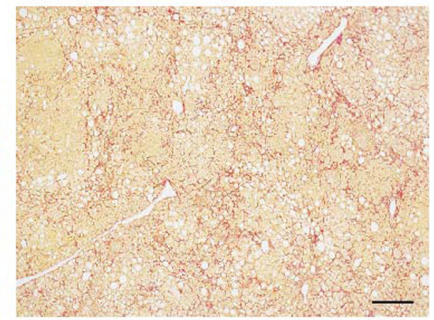

HFD32

12 weeks

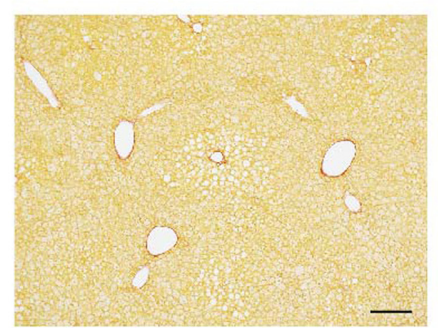

52 weeks

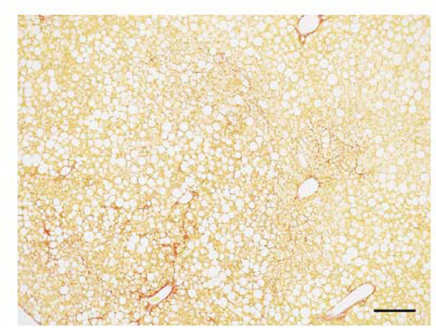

Fig. 5. Fibrotic states in the liver in $A I M^{-1-}$ mice fed the D 09100301 diet: Representative photomicrographs of the liver (Sirius Red staining) in $A I M^{-1-}$ mice fed the D09100301 diet or HFD32 diet for 12 weeks. Scale bars, $200 \mu \mathrm{m}$.

steatosis was induced more prominently by the D09100301 diet than the HFD32 diet. Despite the apparent steatosis and inflammation, typical ballooning changes in hepatocytes were not observed in $\mathrm{AIM}^{-/-}$ mice fed the D09100301 diet. The overall NAFLD activity score [9] reflecting steatosis, inflammation, and ballooning was 3.5 to 4.0 at every analyzed time point in both male and female mice (Fig. 4e).

In parallel with the finding of the inflammatory state, liver fibrosis also progressed in the $A I M^{-/-}$liver when assessed by histology (Fig. 5). The fibrosis was apparently severer in mice fed the D09100301 diet than those fed the HFD32 diet at 12 and 52/60 weeks (Fig. 5), indicating that steatosis-associated inflammation and fibrosis were more prominently promoted in the $\mathrm{AIM}^{-/-}$ liver by the D09100301 diet than by the HFD32 diet.

HCC development in AIM ${ }^{-1-}$ mice fed the D09100301 diet

As we previously reported, all $A I M^{-/-}$mice fed the HFD32 diet for 1 year (52 weeks) exhibited HCC tumor development macroscopically [26]. Similarly, the mice fed a high-fructose diet also revealed a high incidence of HCC tumor development (approximately 70\%) [38].
In contrast, however, none of the $A I M^{-/-}$mice fed the D09100301 diet for 60 weeks harbored macroscopically detectable tumors. On histology, 1 mouse out of 7 had HCC (Fig. 6a), and the other 6 mice had some precancerous regions in the liver, including regions containing a small atypical cell lesion with an unclear border between surrounding normal hepatocytes (Fig. 6b), liver hyperplasia comprising a small nodular region containing non-cancerous hepatocytes with clear borders between surrounding hepatocytes (Fig. 6c), and adenomatous regions exhibiting large nodules that lacked Glisson's capsule, with sharp borders between surrounding hepatocytes (Fig. 6d). Thus, the D09100301 diet likely induces a milder cancerous condition in $A I M^{-/-}$mice than the HFD32 or high-fructose diet.

\section{Discussion}

In this study, we presented $A I M^{-/-}$mice fed the D09100301 diet as a new NAFLD model. AIM suppresses lipid storage within adipocytes and hepatocytes through inactivation of FASN, which results in a decrease in lipid-droplet-coating proteins. Due to this effect, $A I M^{-/-}$mice fed the HFD32 diet (60 kcal\%, most- 
a

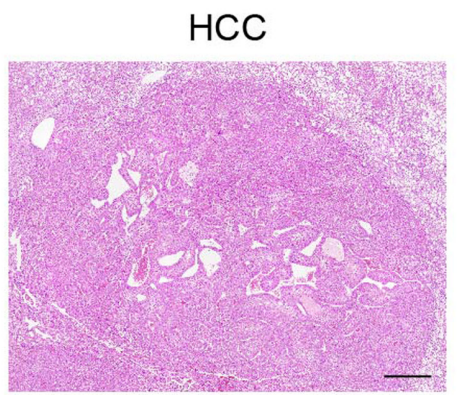

C

Liver hyperplasia

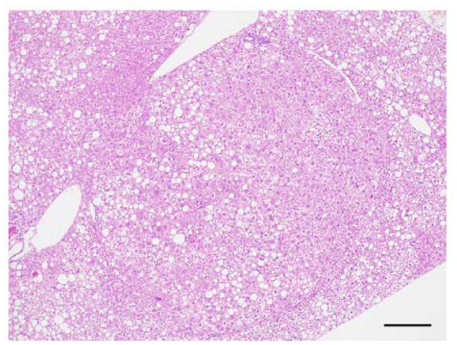

b

Atypical cell region

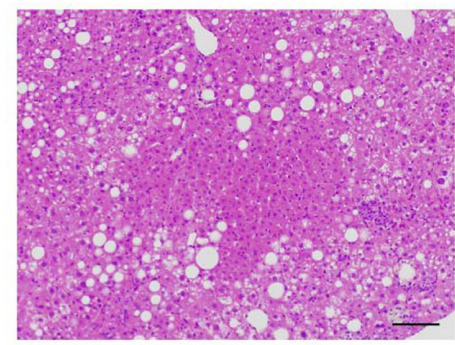

d Adenomatous region

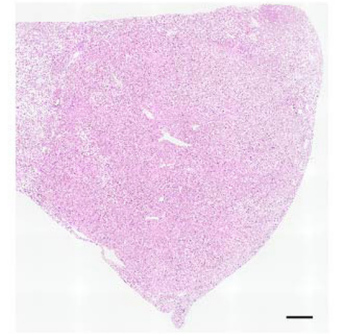

Fig. 6. HCC development in $A I M^{-/-}$mice fed the D09100301 diet: Representative photomicrographs (hematoxylin-eosin staining) of the cancerous (a) and precancerous regions in the liver of $A I M^{-/-}$mice fed the D09100301 diet. (a) HCC. Scale bar, $500 \mu \mathrm{m}$. (b) A small atypical cell lesion. Scale bar, $100 \mu \mathrm{m}$. (c) A hyperplastic site. Scale bar, $200 \mu \mathrm{m}$. (d) An adenomatous region. Scale bar, $500 \mu \mathrm{m}$.

ly lard) exhibited both obesity and liver steatosis, representing a common human NAFLD state [26]. Interestingly, while the HFD32 diet remarkably induces both obesity and liver steatosis, the D09100301 diet affected the liver more prominently than visceral fat. Indeed, the body weight as well as visceral fat weight were significantly smaller after 12 weeks in $A I M^{-/-}$mice fed the D09100301 diet than those fed the HFD32 diet. In addition, the maximum body weight of $A I M^{-/-}$mice brought about by the D09100301 diet for more than 50 weeks was largely similar to that in wild-type mice at the same age maintained with the NCD. In humans, it is well known that there is a population of NAFLD patients who are not classified as obese [37]. Yasutake et al. previously reported that nonobese NAFLD patients exhibit higher serum ALP levels than obese NAFLD patients. In addition, they showed that nonobese NAFLD patients tend to have more cholesterol and $n-6$ unsaturated fatty acids in their diets [48]. These observations in humans are somewhat parallel with the facts that the D09100301 diet contains higher levels of cholesterol and unsaturated fatty acids than the HFD32 diet and that
AIM ${ }^{-/-}$mice fed the D09100301 diet showed high serum levels of ALP and nonesterified fatty acid. Thus, it is likely that $A I M^{-/-}$mice fed the D09100301 diet may be a good model of the human nonobese NAFLD. Although further study is required to clarify the mechanism underlying the liver-predominant lipid storage caused by the D09100301 diet, $A I M^{-/-}$mice fed the D09100301 diet might be a useful tool to understand the disease states of the unique and enigmatic nonobese NAFLD.

In the absence of AIM, hepatocytes that have undergone carcinogenesis are not eliminated efficiently (regardless of the carcinogenic mechanism) and become HCC tumors at a high frequency [26]. Indeed, $A I M^{-/-}$ mice develop multiple $\mathrm{HCC}$ tumors at $100 \%$ frequency when fed the HFD32 diet and at 70\% frequency when fed a high-fructose diet, for a year [26, 38]. It is noteworthy that the lack of AIM does not increase carcinogenicity in the liver, as $A I M^{-/-}$mice fed the NCD do not exhibit HCC tumors. Thus, $A I M^{-1-}$ mice are an excellent monitoring tool to assess the carcinogenicity of various loads including diets, chemicals, and environments. It is intriguing that $A I M^{-/-}$mice fed the D09100301 diet 
showed a far lower incidence of HCC tumors than mice fed the HFD32 diet, despite the comparable steatosis levels among them and an even more accelerated liver inflammatory state in the D09100301 diet-fed mice. In the absence of AIM, the overall incidence of HCC tumor represents the level of hepatocyte carcinogenesis differentially caused by each type of diet. Therefore, it is very likely that the reason why the HCC tumor incidence was low in $A I M^{-/-}$mice fed the D09100301 diet is the lower promotion of carcinogenesis by the D09100301 diet. Another plausible explanation for this paradoxical phenotype might be that the mice fed the D09100301 diet were less obese than mice fed the HFD32 diet. It might be worth reemphasizing that the body weight of $A I M^{-1-}$ mice fed the D09100301 diet was essentially comparable to that of wild-type mice at the same age maintained with the NCD. In humans, obesity has been established as an important risk factor for the development of various types of malignancies, including liver cancer [2, 9, 11, 12, 18, 23, 25, 28, 32, 37, 38, 41, 46-48]. Calle et al. used a large prospective study cohort of adults in the US to assess the relationship between obesity and mortality from various cancers [13]. They demonstrated that compared with patients with a normal body mass index (BMI), the relative risk of mortality from liver cancer was 4.52 times higher in men and 1.68 times higher in women with a BMI $>35 \mathrm{~kg} / \mathrm{m}^{2}$. Similar reports have been accumulating from large-scale clinical studies in different countries, including Denmark, Korea, and Japan $[31,34,35]$. These observations may support our current results, which showed that both weight gain and HCC tumor incidence were lower in $A I M^{-/-}$mice fed the D09100301 diet than in mice fed the HFD32 diet. The risk posed by obesity for HCC development may be conferred by two different factors: accelerated progression of NAFLD severity and increased carcinogenic potential of obesity alone [10]. In $A I M^{-/-}$mice, based on the comparable steatosis and rather accelerated inflammatory state promoted by the D09100301 diet, it is likely that the less-obese state might decrease the risk of HCC tumor development independently of the condition of NAFLD. The mechanism by which obesity alone increases the risk of $\mathrm{HCC}$ in both humans and mice is yet unknown; thus, further efforts will be needed to clarify the issue. The constitutive, chronic inflammation in many organs brought about by obesity might be an important reason [41].

In summary, our study demonstrated that $A I M^{-/-}$mice fed the D09100301 diet could be a tool for studies of nonobese NAFLD with less HCC development. This model has the potential to open the door to clarifying not only the pathophysiology of nonobese NAFLD but also the mechanistic link between obesity and HCC development.

\section{Acknowledgments}

We thank Dr. T. Okanoue for helpful advice and discussion. This work was supported by AMED-CREST, Japan Agency for Medical Research Development (to T.M.), and Grant-in-Aid for Scientific Research (S) Grant number 16H06389 (to T.M.), Ministry of Education, Culture, Sports, Science and Technology, Japan.

\section{References}

1. Angulo, P. 2002. Nonalcoholic fatty liver disease. N. Engl. $J$. Med. 346: 1221-1231. [Medline] [CrossRef]

2. Arai, S. and Miyazaki, T. 2014. Impacts of the apoptosis inhibitor of macrophage (AIM) on obesity-associated inflammatory diseases. Semin. Immunopathol. 36: 3-12. [Medline] [CrossRef]

3. Arai, S., Maehara, N., Iwamura, Y., Honda, S., Nakashima, K., Kai, T., Ogishi, M., Morita, K., Kurokawa, J., Mori, M., Motoi, Y., Miyake, K., Matsuhashi, N., Yamamura, K., Ohara, O., Shibuya, A., Wakeland, E.K., Li, Q.Z. and Miyazaki, T. 2013. Obesity-associated autoantibody production requires AIM to retain the immunoglobulin $\mathrm{M}$ immune complex on follicular dendritic cells. Cell Rep. 3: 1187-1198. [Medline] [CrossRef]

4. Argo, C.K. and Caldwell, S.H. 2009. Epidemiology and natural history of non-alcoholic steatohepatitis. Clin. Liver Dis. 13: 511-531. [Medline] [CrossRef]

5. Ascha, M.S., Hanouneh, I.A., Lopez, R., Tamimi, T.A., Feldstein, A.F. and Zein, N.N. 2010. The incidence and risk factors of hepatocellular carcinoma in patients with nonalcoholic steatohepatitis. Hepatology 51: 1972-1978. [Medline] [CrossRef]

6. Bacon, B.R., Farahvash, M.J., Janney, C.G. and Neuschwander-Tetri, B.A. 1994. Nonalcoholic steatohepatitis: an expanded clinical entity. Gastroenterology 107: 1103-1109. [Medline] [CrossRef]

7. Blonski, W., Kotlyar, D.S. and Forde, K.A. 2010. Non-viral causes of hepatocellular carcinoma. World J. Gastroenterol. 16: 3603-3615. [Medline] [CrossRef]

8. Bosch, F.X., Ribes, J., Cléries, R. and Díaz, M. 2005. Epidemiology of hepatocellular carcinoma. Clin. Liver Dis. 9: 191-211. [Medline] [CrossRef]

9. Brunt, E.M., Kleiner, D.E., Wilson, L.A., Belt, P., Neuschwander-Tetri, B.A., NASH Clinical Research Network (CRN) 2011. Nonalcoholic fatty liver disease (NAFLD) activity score and the histopathologic diagnosis 
in NAFLD: distinct clinicopathologic meanings. Hepatology 53: 810-820. [Medline] [CrossRef]

10. Bugianesi, E. 2007. Non-alcoholic steatohepatitis and cancer. Clin. Liver Dis. 11: 191-207. [Medline] [CrossRef]

11. Bugianesi, E., Leone, N., Vanni, E., Marchesini, G., Brunello, F., Carucci, P., Musso, A., De Paolis, P., Capussotti, L., Salizzoni, M. and Rizzetto, M. 2002. Expanding the natural history of nonalcoholic steatohepatitis: from cryptogenic cirrhosis to hepatocellular carcinoma. Gastroenterology 123: 134-140. [Medline] [CrossRef]

12. Caldwell, S.H., Crespo, D.M., Kang, H.S. and Al-Osaimi, A.M. 2004. Obesity and hepatocellular carcinoma. Gastroenterology 127:(Suppl 1): S97-S103. [Medline] [CrossRef]

13. Calle, E.E., Rodriguez, C., Walker-Thurmond, K. and Thun, M.J. 2003. Overweight, obesity, and mortality from cancer in a prospectively studied cohort of U.S. adults. N. Engl. J. Med. 348: 1625-1638. [Medline] [CrossRef]

14. Chagas, A.L., Kikuchi, L.O., Oliveira, C.P., Vezozzo, D.C., Mello, E.S., Oliveira, A.C., Cella, L.C., Herman, P., Bachella, T., Caldwell, S.H., Alves, V.A. and Carrilho, F.J. 2009. Does hepatocellular carcinoma in non-alcoholic steatohepatitis exist in cirrhotic and non-cirrhotic patients? Braz. J. Med. Biol. Res. 42: 958-962. [Medline] [CrossRef]

15. Day, C.P. and Saksena, S. 2002. Non-alcoholic steatohepatitis: definitions and pathogenesis. J. Gastroenterol. Hepatol. 17:(Suppl 3): S377-S384. [Medline] [CrossRef]

16. El-Serag, H.B. and Rudolph, K.L. 2007. Hepatocellular carcinoma: epidemiology and molecular carcinogenesis. Gastroenterology 132: 2557-2576. [Medline] [CrossRef]

17. Ibrahim, S.H., Hirsova, P., Malhi, H. and Gores, G.J. 2016. Animal Models of Nonalcoholic Steatohepatitis: Eat, Delete, and Inflame. Dig. Dis. Sci. 61: 1325-1336. [Medline] [CrossRef]

18. Iwamura, Y., Mori, M., Nakashima, K., Mikami, T., Murayama, K., Arai, S. and Miyazaki, T. 2012. Apoptosis inhibitor of macrophage (AIM) diminishes lipid droplet-coating proteins leading to lipolysis in adipocytes. Biochem. Biophys. Res. Commun. 422: 476-481. [Medline] [CrossRef]

19. Jemal, A., Bray, F., Center, M.M., Ferlay, J., Ward, E. and Forman, D. 2011. Global cancer statistics. CA Cancer J. Clin. 61: 69-90. [Medline] [CrossRef]

20. Kawada, N., Imanaka, K., Kawaguchi, T., Tamai, C., Ishihara, R., Matsunaga, T., Gotoh, K., Yamada, T. and Tomita, Y. 2009. Hepatocellular carcinoma arising from non-cirrhotic nonalcoholic steatohepatitis. J. Gastroenterol. 44: 11901194. [Medline] [CrossRef]

21. Kleiner, D.E., Brunt, E.M., Van Natta, M., Behling, C., Contos, M.J., Cummings, O.W., Ferrell, L.D., Liu, Y.C., Torbenson, M.S., Unalp-Arida, A., Yeh, M., McCullough, A.J., Sanyal, A.J., Nonalcoholic Steatohepatitis Clinical Research Network 2005. Design and validation of a histological scoring system for nonalcoholic fatty liver disease. Hepatology 41: 1313-1321. [Medline] [CrossRef]

22. Koyama, N., Yamazaki, T., Kanetsuki, Y., Hirota, J., Asai, T., Mitsumoto, Y., Mizuno, M., Shima, T., Kanbara, Y., Arai, S., Miyazaki, T. and Okanoue, T. 2018. Activation of apoptosis inhibitor of macrophage is a sensitive diagnostic marker for NASH-associated hepatocellular carcinoma. J. Gastroen- terol. 53: 770-779. [Medline]

23. Kurokawa, J., Arai, S., Nakashima, K., Nagano, H., Nishijima, A., Miyata, K., Ose, R., Mori, M., Kubota, N., Kadowaki, T., Oike, Y., Koga, H., Febbraio, M., Iwanaga, T. and Miyazaki, T. 2010. Macrophage-derived AIM is endocytosed into adipocytes and decreases lipid droplets via inhibition of fatty acid synthase activity. Cell Metab. 11: 479-492. [Medline] [CrossRef]

24. Lazo, M. and Clark, J.M. 2008. The epidemiology of nonalcoholic fatty liver disease: a global perspective. Semin. Liver Dis. 28: 339-350. [Medline] [CrossRef]

25. Lew, E.A. and Garfinkel, L. 1979. Variations in mortality by weight among 750,000 men and women. J. Chronic Dis. 32: 563-576. [Medline] [CrossRef]

26. Maehara, N., Arai, S., Mori, M., Iwamura, Y., Kurokawa, J., Kai, T., Kusunoki, S., Taniguchi, K., Ikeda, K., Ohara, O., Yamamura, K.I. and Miyazaki, T. 2014. Circulating AIM prevents hepatocellular carcinoma through complement activation. Cell Rep. 9: 61-74. [Medline] [CrossRef]

27. Matteoni, C.A., Younossi, Z.M., Gramlich, T., Boparai, N., Liu, Y.C. and McCullough, A.J. 1999. Nonalcoholic fatty liver disease: a spectrum of clinical and pathological severity. Gastroenterology 116: 1413-1419. [Medline] [CrossRef]

28. Miyazaki, T. and Arai, S. 2015. Tricking an ancient immune function to eradicate hepatocellular carcinoma. Mol. Cell. Oncol. 2: e985915. [Medline] [CrossRef]

29. Miyazaki, T., Hirokami, Y., Matsuhashi, N., Takatsuka, H. and Naito, M. 1999. Increased susceptibility of thymocytes to apoptosis in mice lacking AIM, a novel murine macrophage-derived soluble factor belonging to the scavenger receptor cysteine-rich domain superfamily. J. Exp. Med. 189: 413-422. [Medline] [CrossRef]

30. Miyazaki, T., Yamazaki, T., Sugisawa, R., Gershwin, M.E. and Arai, S. 2018. AIM associated with the IgM pentamer: attackers on stand-by at aircraft carrier. Cell. Mol. Immunol. 15: 563-574 [CrossRef]. [Medline]

31. Møller, H., Mellemgaard, A., Lindvig, K. and Olsen, J.H. 1994. Obesity and cancer risk: a Danish record-linkage study. Eur. J. Cancer 30A: 344-350. [Medline] [CrossRef]

32. Neels, J.G. and Olefsky, J.M. 2006. Inflamed fat: what starts the fire? J. Clin. Invest. 116: 33-35. [Medline] [CrossRef]

33. Nordenstedt, H., White, D.L. and El-Serag, H.B. 2010. The changing pattern of epidemiology in hepatocellular carcinoma. Dig. Liver Dis. 42:(Suppl 3): S206-S214. [Medline] [CrossRef]

34. Oh, S.W., Yoon, Y.S. and Shin, S.A. 2005. Effects of excess weight on cancer incidences depending on cancer sites and histologic findings among men: Korea National Health Insurance Corporation Study. J. Clin. Oncol. 23: 4742-4754. [Medline] [CrossRef]

35. Ohki, T., Tateishi, R., Shiina, S., Goto, E., Sato, T., Nakagawa, H., Masuzaki, R., Goto, T., Hamamura, K., Kanai, F., Yoshida, H., Kawabe, T. and Omata, M. 2009. Visceral fat accumulation is an independent risk factor for hepatocellular carcinoma recurrence after curative treatment in patients with suspected NASH. Gut 58: 839-844. [Medline] [CrossRef]

36. Okanoue, T., Umemura, A., Yasui, K. and Itoh, Y. 2011. Non- 
alcoholic fatty liver disease and nonalcoholic steatohepatitis in Japan. J. Gastroenterol. Hepatol. 26:(Suppl 1): 153-162. [Medline] [CrossRef]

37. Omagari, K., Kadokawa, Y., Masuda, J., Egawa, I., Sawa, T., Hazama, H., Ohba, K., Isomoto, H., Mizuta, Y., Hayashida, K., Murase, K., Kadota, T., Murata, I. and Kohno, S. 2002. Fatty liver in non-alcoholic non-overweight Japanese adults: incidence and clinical characteristics. J. Gastroenterol. Hepatol. 17: 1098-1105. [Medline] [CrossRef]

38. Ozawa, T., Maehara, N., Kai, T., Arai, S. and Miyazaki, T. 2016. Dietary fructose-induced hepatocellular carcinoma development manifested in mice lacking apoptosis inhibitor of macrophage (AIM). Genes Cells 21: 1320-1332. [Medline] [CrossRef]

39. Powell, E.E., Cooksley, W.G., Hanson, R., Searle, J., Halliday, J.W. and Powell, L.W. 1990. The natural history of nonalcoholic steatohepatitis: a follow-up study of forty-two patients for up to 21 years. Hepatology 11: 74-80. [Medline] [CrossRef]

40. Sakamoto, M., Tsujikawa, H., Effendi, K., Ojima, H., Harada, K., Zen, Y., Kondo, F., Nakano, M., Kage, M., Sumida, Y., Hashimoto, E., Yamada, G., Okanoue, T. and Koike, K. 2017. Pathological findings of nonalcoholic steatohepatitis and nonalcoholic fatty liver disease. Pathol. Int. 67: 1-7. [Medline] [CrossRef]

41. Starley, B.Q., Calcagno, C.J. and Harrison, S.A. 2010. Nonalcoholic fatty liver disease and hepatocellular carcinoma: a weighty connection. Hepatology 51: 1820-1832. [Medline] [CrossRef]

42. Torres, D.M. and Harrison, S.A. 2012. Nonalcoholic steatohepatitis and noncirrhotic hepatocellular carcinoma: fertile soil. Semin. Liver Dis. 32: 30-38. [Medline] [CrossRef]

43. Tsuneyama, K., Nishitsuji, K., Matsumoto, M., Kobayashi,
T., Morimoto, Y., Tsunematsu, T. and Ogawa, H. 2017. Animal models for analyzing metabolic syndrome-associated liver diseases. Pathol. Int. 67: 539-546. [Medline] [CrossRef]

44. Van Herck, M.A., Vonghia, L. and Francque, S.M. 2017. Animal Models of Nonalcoholic Fatty Liver Disease-A Starter's Guide. Nutrients 9: E1072. [Medline] [CrossRef]

45. Williams, C.D., Stengel, J., Asike, M.I., Torres, D.M., Shaw, J., Contreras, M., Landt, C.L. and Harrison, S.A. 2011. Prevalence of nonalcoholic fatty liver disease and nonalcoholic steatohepatitis among a largely middle-aged population utilizing ultrasound and liver biopsy: a prospective study. Gastroenterology 140: 124-131. [Medline] [CrossRef]

46. Wolk, A., Gridley, G., Svensson, M., Nyrén, O., McLaughlin, J.K., Fraumeni, J.F. and Adam, H.O. 2001. A prospective study of obesity and cancer risk (Sweden). Cancer Causes Control 12: 13-21. [Medline] [CrossRef]

47. Yamazaki, T., Mori, M., Arai, S., Tateishi, R., Abe, M., Ban, M., Nishijima, A., Maeda, M., Asano, T., Kai, T., Izumino, K., Takahashi, J., Aoyama, K., Harada, S., Takebayashi, T., Gunji, T., Ohnishi, S., Seto, S., Yoshida, Y., Hiasa, Y., Koike, K., Yamamura, K., Inoue, K. and Miyazaki, T. 2014. Circulating AIM as an indicator of liver damage and hepatocellular carcinoma in humans. PLoS One 9: e109123. [Medline] [CrossRef]

48. Yasutake, K., Nakamuta, M., Shima, Y., Ohyama, A., Masuda, K., Haruta, N., Fujino, T., Aoyagi, Y., Fukuizumi, K., Yoshimoto, T., Takemoto, R., Miyahara, T., Harada, N., Hayata, F., Nakashima, M. and Enjoji, M. 2009. Nutritional investigation of non-obese patients with non-alcoholic fatty liver disease: the significance of dietary cholesterol. Scand. J. Gastroenterol. 44: 471-477. [Medline] [CrossRef] 